\title{
$x^{\prime}: \quad \ldots+4$
}

BDX $-613-2114$

Distrioution Gtegort U $C-25$

\section{FEASTIBILITY OF ELECTROPLATED GOLD FOR HYBRID MICROCIRCUITS}

\author{
By P. L. Blessner \\ The Bendix Corporation, \\ Kansas City Division*
}

Summary

\section{MASTER}

Vacuum evaporated gold is presently used by. Bendix Kansas City for $3 \mu \mathrm{m}$ and $6 \mu \mathrm{m}$ metallization layers on hybrid microcircuit (HMC) substrates. Some future RF HMCs will require gold thicknesses greater than $6 \mu \mathrm{m}$. Since vacuum evaporation is neither technically - nor economically feasible for producing gold films much greater. than $6 \mu \mathrm{m}$, electroplating was investigated as an alternative method of providing the thick gold films required. Because electroplated gold has never been used for HMC substrate metalizization at Bendix Kansas City, this feasibility study was also designed to determine the characteristics of electroplated gold and its compatibility with present HMC fabrication processes.

Ceramic substrates 95 by $114 \mathrm{~mm}$ ( 3.75 by $4.5 \mathrm{in}$. ) were electroplated with 6,10 , and $25 \mu \mathrm{m}$ of gold after $0.02 \mu \mathrm{m}$ of chromium and $0.5 \mu \mathrm{m}$ of gold had been either sputtered or vacuum evaporated onto the substrate surfaces. Substrates vacuum evaporated with $6 \mu \mathrm{m}$ of gold were used as a control group. The substrates were evaluated for via resistance, $\mathrm{RF}$ electrical characteristics, conductor definition and resolution, solder wettability, thermocompression bondability, and environmental stability.

For $6 \mu \mathrm{m}$ thick films, the electrical resistance of electroplated vias was almost an order of magnitude lower than that of evaporated vias. Green punched holes had essentially the same via resistance as ultrasonically drilled holes (of the same diameter) when metallized with electroplated gold. The thickness uniformity of the electroplated films was not as good as that of evaporated films; however, this can be improved by modifying the plating fixture. The RF electrical characteristics, conductor definition and resolution, solderability, thermocompression bondability, and environmental stability of the electroplated gold were all comparable to those qualities of the evaporated gold.

Based on this study, electroplated gold appears to be a feasible alternative to vacuum evaporated gold for use on HMC substrates.

\footnotetext{
*Operated by the U. S. Department of Energy by The Bendix Corporation, Kansas Cïty Divisioh, under Contract No. DE-AC04-76-DPOOG13. This paper was supported by the Division of Military Application:
} 


\section{DISCLAIMER}

This report was prepared as an account of work sponsored by an agency of the United States Government. Neither the United States Government nor any agency Thereof, nor any of their employees, makes any warranty, express or implied, or assumes any legal liability or responsibility for the accuracy, completeness, or usefulness of any information, apparatus, product, or process disclosed, or represents that its use would not infringe privately owned rights. Reference herein to any specific commercial product, process, or service by trade name, trademark, manufacturer, or otherwise does not necessarily constitute or imply its endorsement, recommendation, or favoring by the United States Government or any agency thereof. The views and opinions of authors expressed herein do not necessarily state or reflect those of the United States Government or any agency thereof. 


\section{DISCLAIMER}

Portions of this document may be illegible in electronic image products. Images are produced from the best available original document. 
The purpose of this project was to evaluate the suitability of electroplated gold for use on HMC substrates. Vacuum evaporation is presently used to provide gold metallization 3 and $6 \mu \mathrm{m}$ thick. It is expected that some future RF HMCs will require gold films greater than $10 \mu \mathrm{m}$ thick. Since the vacuum evaporation process is neither technically nor economically feasible for producing films of this thickness, electroplating was investigated as one approach to provide the thick gold films required.

This project evaluated the properties of electroplated gold films. related to HMC requirements, while the electroplating process itself was investigated separately. The investigation included 6 , 10, and $25 \mu \mathrm{m}$ thick gold films which had been electroplated over sputtered or vacuum evaporated layers of chromium and gold. These films were then tested for via resistance, solderability, thermocompression bondability, RF electrical characteristics, conductor definition and resolution, and environmental stability. The same properties were measured on a control group of substrates having $6 \mu \mathrm{m}$ of vacuum evaporated gold.

A total of forty-eight 95 by $114 \mathrm{~mm}$ ( 3.75 by 4.5 in.) substrates were used in this study. All were taken from a single lot of 99.6 percent alumina substrates. They were subjected to the typical sequence of HMC processes: stamp and bake serial number on back side, clean, bake at $900^{\circ} \mathrm{C}$, and sputter tantalum nitride on front side. The substrates were then metallized with either vacuum evaporated or sputtered chromium and gold (Table 1). A range of values is given in Table 1 when more than one metallization lot was run. The substrates with $0.5 \mu \mathrm{m}$ of gold were then electroplated with 6,10 , or $25 \mu \mathrm{m}$ of gold using a high purity neutral plating solution operated at the following parameters: $60^{\circ} \mathrm{C}$ bath temperature, $6.5 \mathrm{pH}$, and 0.002 to $0.003 \mathrm{~A} / \mathrm{m}^{2}$ current density.

\section{Film Physical Properties}

Electroplated and evaporated gold films were examined and compared on the basis of three properties: film thickness and sheet resistivity, surface topography, and composition.

Beta backscatter techniques were used.to measure film thickness in five locations on both the front and back sides of substrates. Measurements were performed only on $6 \mu \mathrm{m}$ evaporated and electro-plated gold since thickness standards were not available for 10 and $25 \mu \mathrm{m}$ thick films.

Out of 4 electroplated substrates, the gold thickness from substrate to substrate ranged from 6.0 to $8.1 \mu \mathrm{m}$, with an average thickness of $7.0 \mu \mathrm{m}$. The maximum variation on one side of a substrate was $1.2 \mu \mathrm{m}$, or 18 percent of the average thickness on 
Table 1.: Metallization Process Parameters

Deposition

Method

and

Quantity of

Substrates
Nominal

Thickness

( $\mathrm{nm}$ )
Deposition

Rate $(\mathrm{nm} / \mathrm{min})$
Maximum

Substrate

Temperature

$\left({ }^{\circ} \mathrm{C}\right)$

Chromium

\begin{tabular}{llll}
\hline Evaporation (13) & 30 & $37-45$ & 225 \\
Evaporation (20) & 30 & $40-61$ & 225 \\
Sputtering (15) & 60 & 30 & $*$ \\
\hline
\end{tabular}

Gold

\begin{tabular}{llll}
\hline Evaporation (13) & 6 & $129-283$ & $290-335$ \\
Evaporation $(20)$ & 0.5 & $166-309$ & $250-270$ \\
Sputtering $(15)$ & 0.6 & 110 & $*$ \\
\hline
\end{tabular}

*Not Measured

that side. Out of 14 evaporated substrates, the thickness ranged from 5.9 to $8.5 \mu \mathrm{m}$, with an average of $7.4 \mu \mathrm{m}$. The maximum variation on a given side was $0.6 \mu \mathrm{m}$, or 8 percent of the average thickness on that side.

Similar variations were found for the sheet resistivity. On an electroplated substrate having an average gold thickness of $7.2 \mu \mathrm{m}$, the average sheet resistivity was $3.5 \mathrm{~m} \Omega /$ square, compared to $3.8 \mathrm{~m} \Omega /$ square for an evaporated substrate with a $7.0 \mu \mathrm{m}$ average thickness.

The data indicates that electroplating produced a larger variation in film thickness across a given substrate surface in comparison to the evaporation system geometry used in this study; however, it is more repeatable from substrate to substrate than vacuum evaporation. Thickness variations as low as 2 percent have beeri achieved with electroplating, and modifications to the plating fixture should produce HMCs approaching this value. 
The surface topography of the films was examined using a scanning electron microscope (SEM). SEM photographs of electroplated and: evaporated films 7 and $8 \mu \mathrm{m}$ thick are shown in Figure 1 . The. electroplated film appears to be much less porous than the evaporated film because of the greater intergranular growth. Photographs of the structure of 10 and $25 \mu \mathrm{m}$ thick electroplated films indicate that the grain size at the surface of the film increases as the film thickness increases (Figure 2).

Auger Electron Spectroscopy (AES) was used to examine the composition of the gold films. Spectrographs of $6 \mu \mathrm{m}$ evaporated and electroplated films, taken after the films had been stabilized for 2 hours at $300^{\circ} \mathrm{C}$, are shown in Figures 3 and 4 . The graphs of the two substrates are almost identical, showing that chromium had diffused to the surface of both films. The other elements detected are the result of handling and storage in plastic bags. After sputtering off the surface of the films, chromium was not detected on either type of film (Figures 5 and 6 ).

This project did not attempt to modify the plating conditions to improve the properties of the gold films. If the diffusion of the chromium occurs along the grain boundaries of the gold, it might be possible to produce an electroplated gold structure which will reduce or prevent chromium migration to the surface of the gold. ${ }^{1}, 2$

\section{RF Characteristics}

A total of 24 substrates were used to evaluate the RF electrical characteristics of electroplated gold films and compare them to those of evaporated gold films. Two substrates 51 by $51 \mathrm{~mm}$ ( 2 by 2 in.) were scribed from each of 12 larger substrates. An RF test pattern was photo-processed on each substrate. The test pattern consisted of a meandering stripline with a total length of $395 \mathrm{~mm}$ ( $15.566 \mathrm{in.}$ ).

An aluminum test fixture was made for mounting the substrates during electrical testing. The air gap between the bottom surface of the substrate and the inner surface of the aluminum cover was $4.8 \mathrm{~mm}$ ( 0.190 in.) which is typical for RF HMCs. Measurements were made on an automatic network analyzer system. To eliminate any variations in data resulting from calibration, all 24 substrates were tested consecutively without recalibrating the system. Measurements were taken at $100 \mathrm{MHz}$ intervals between 100 and $2000 \mathrm{MHz}$.

The attenuation values were measured in decibels and converted to linear values for determining the average attenuation at a given. frequency for each metallization type and thickness. The typical loss through a pair of connectors, $0.13 \mathrm{db}$, was subtracted from these average values. The values were then divided by the physical 

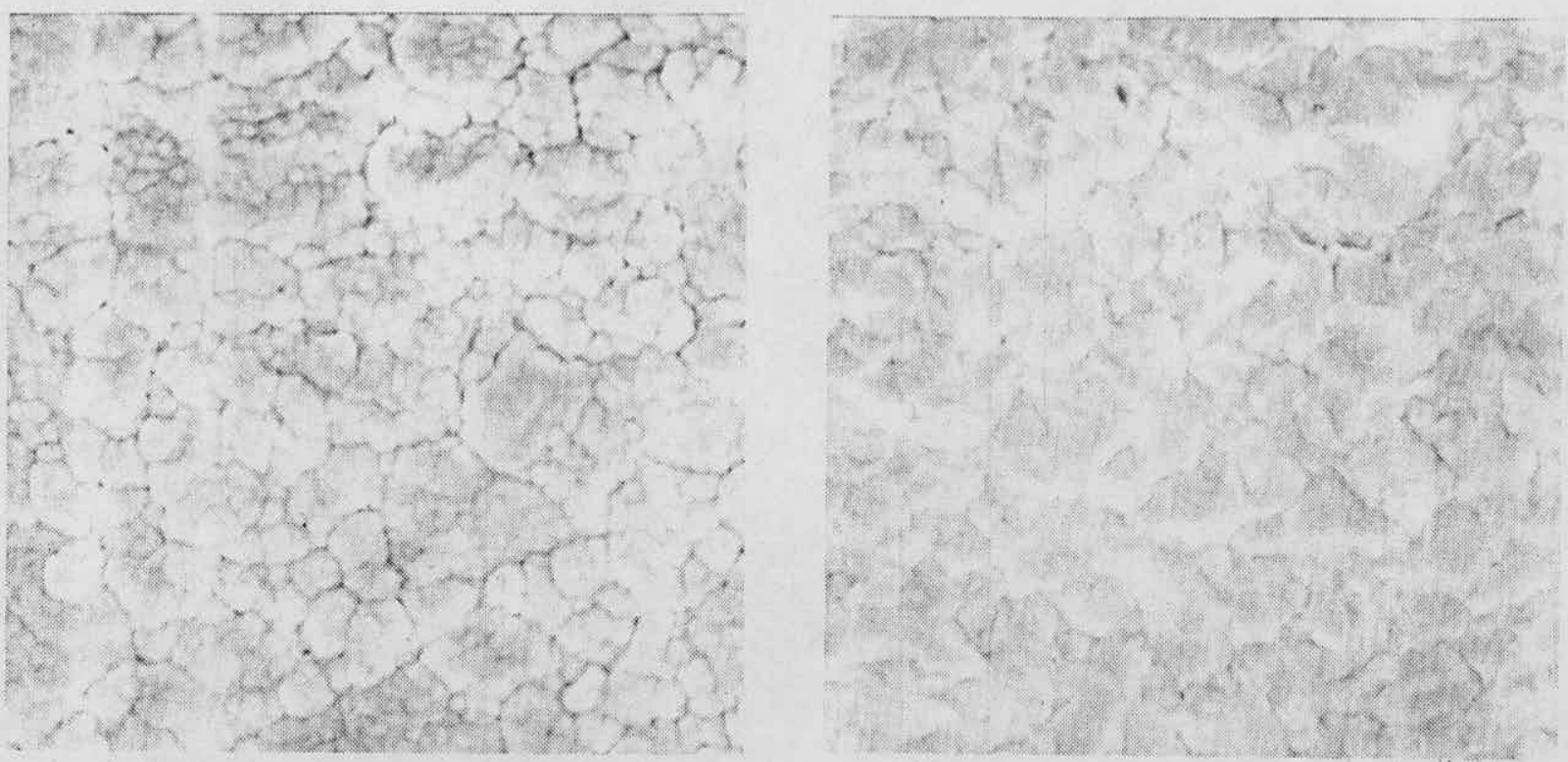

Figure 1. SEM Views of Structure of 8 um Evaporated (Left) and $7 \mu \mathrm{m}$ Electroplated (Right) Gold Film (5000X)
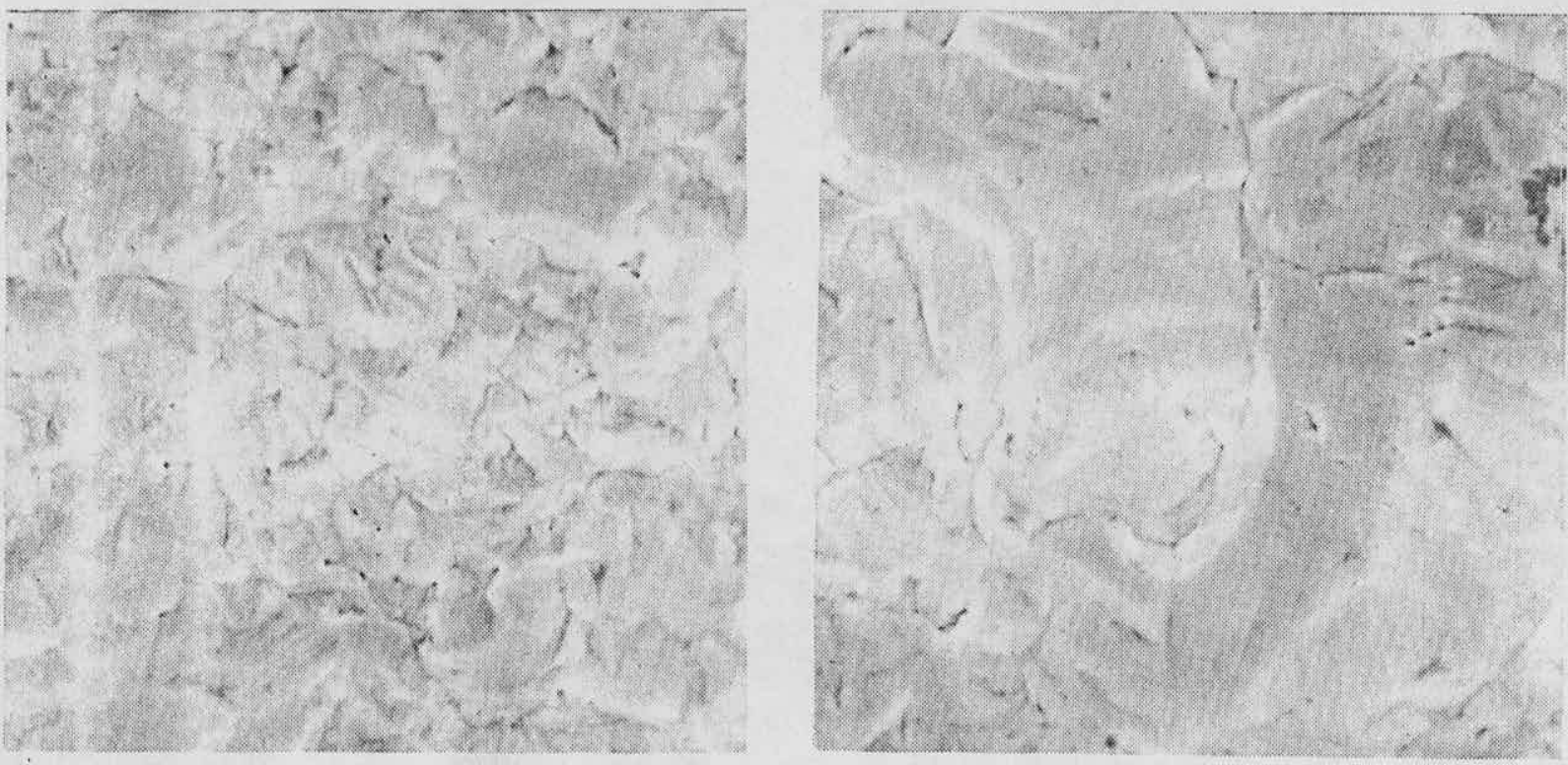

Figure 2. SEM Views of Structure of 10 (Left) and $25 \mu \mathrm{m}$ (Right) Electroplated Gold Film (5000X) 


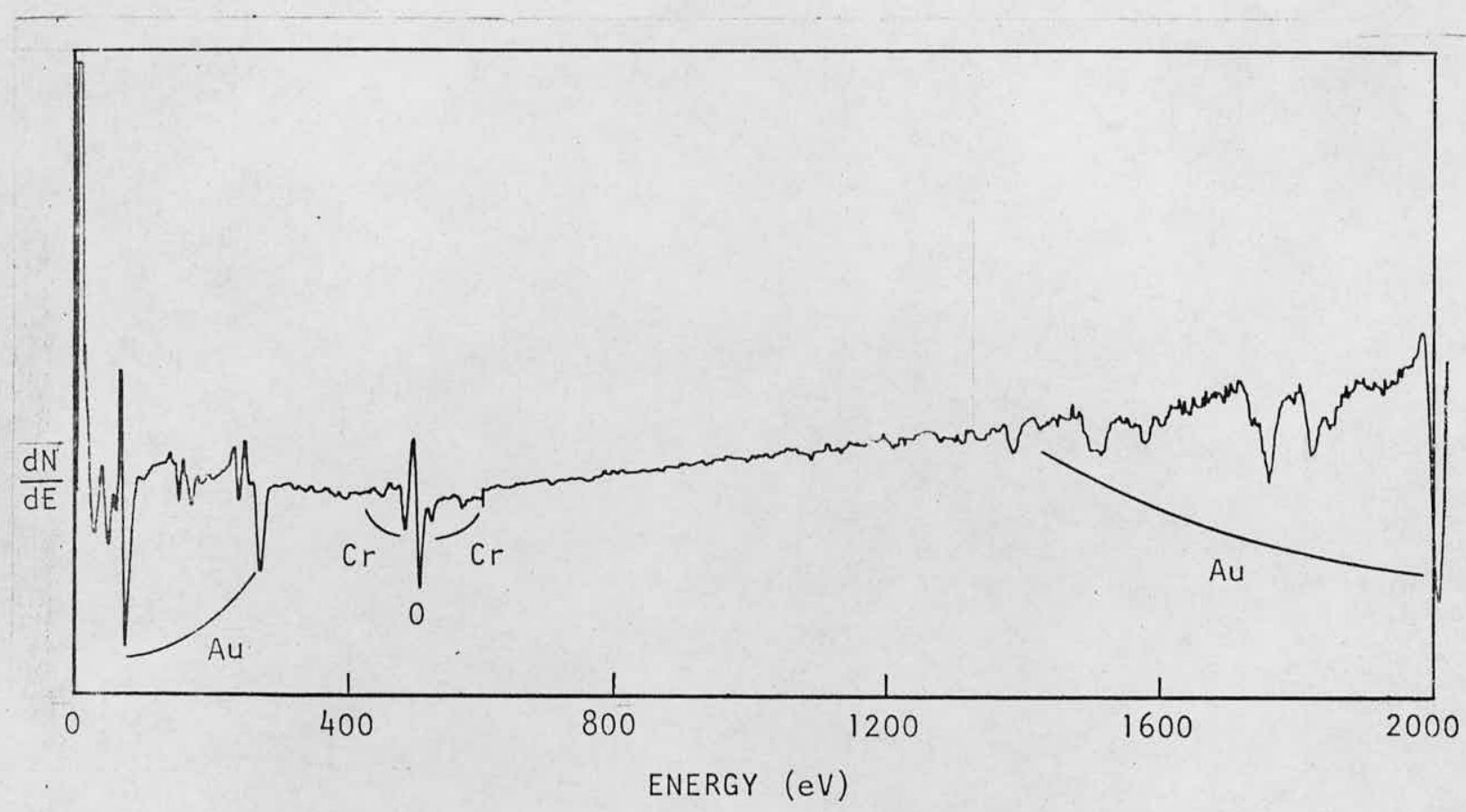

Figure 3. Auger Spectrograph of $6 \mu \mathrm{m}$ Evaporated Gold Film After Stabilization

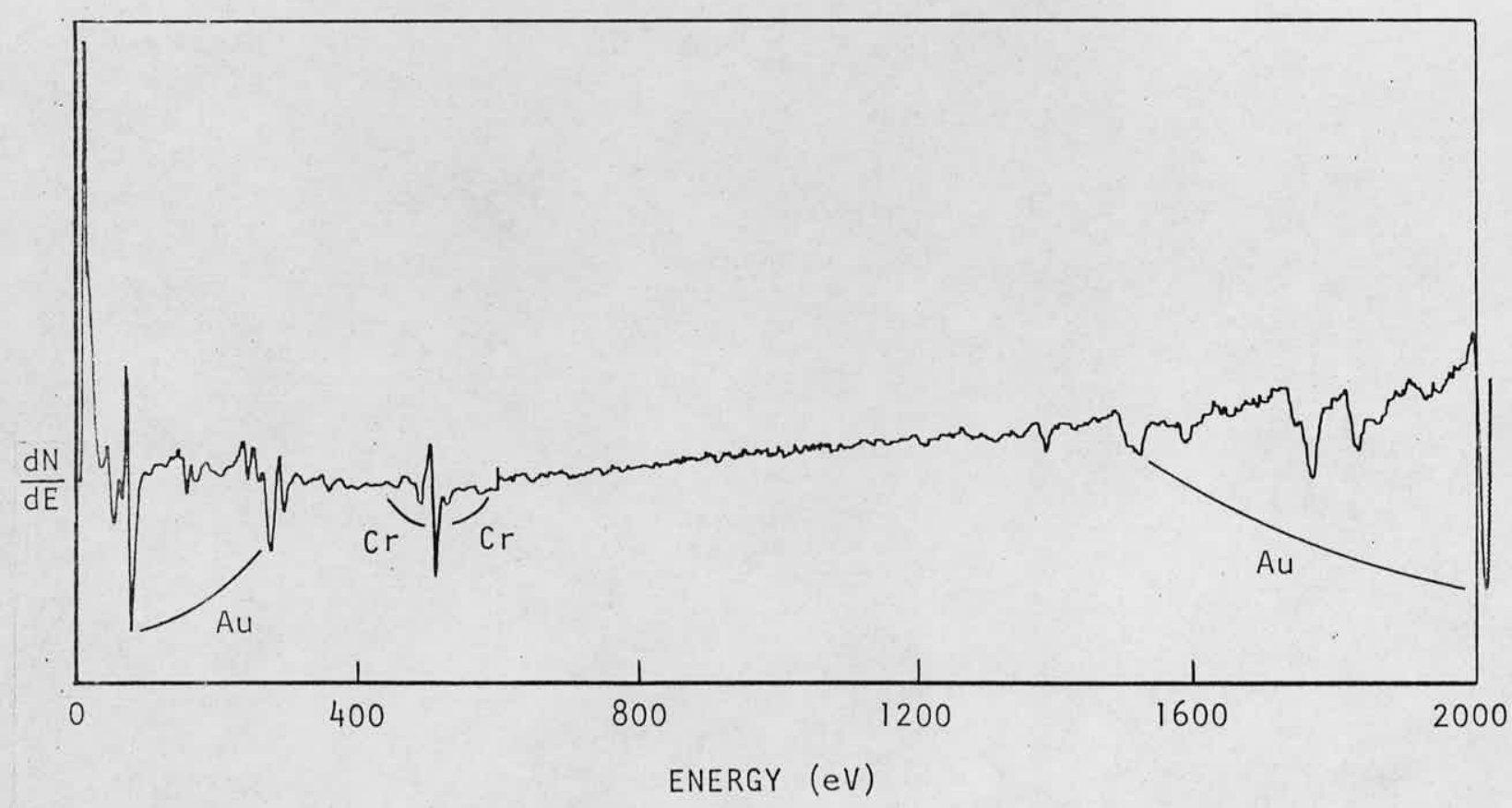

Figure 4. Auger Spectrograph of $6 \mu \mathrm{m}$ Electroplated Gold Film After Stabilization 


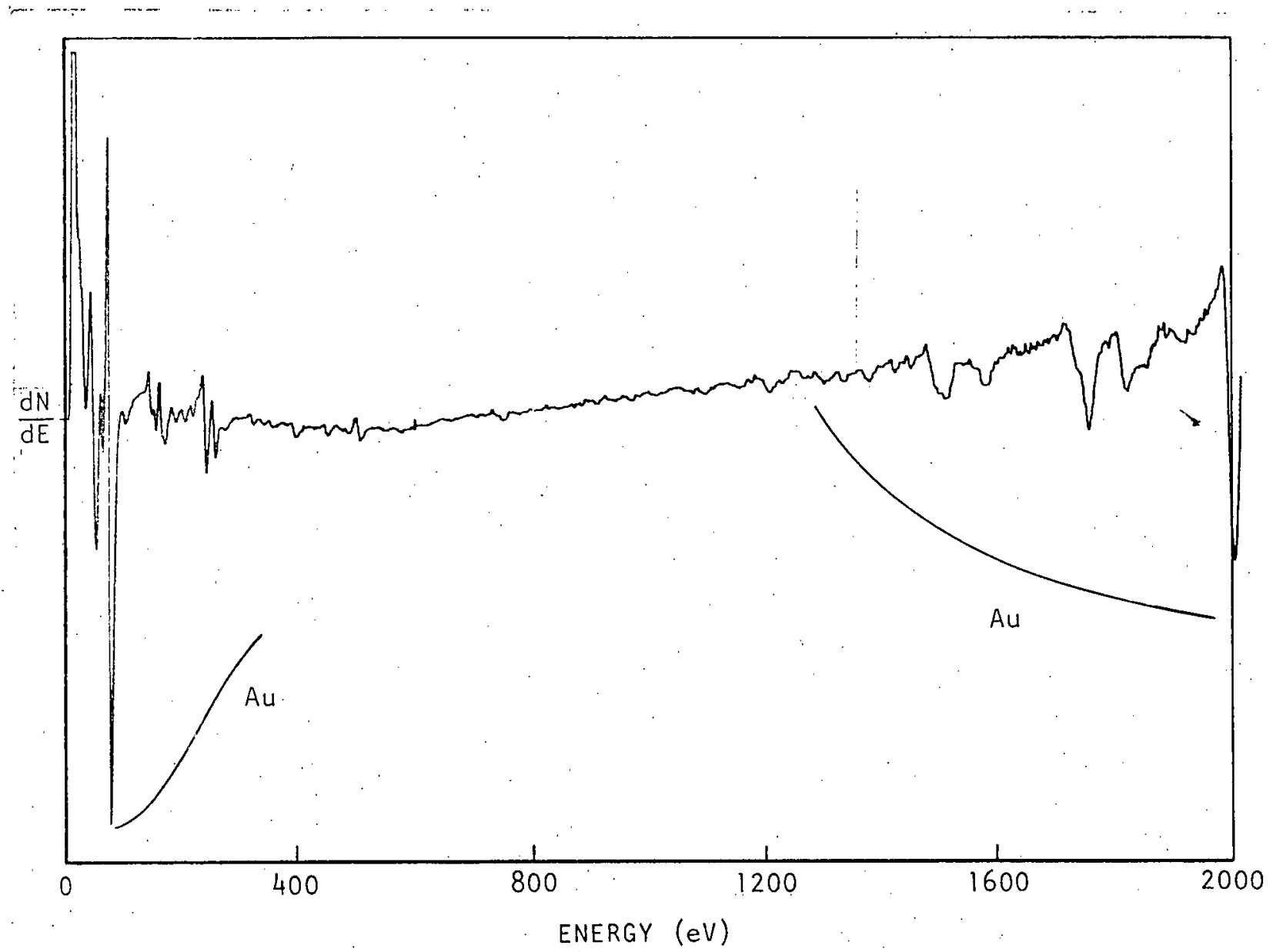

Figure 5. Auger Spectrograph of $6 \mu \mathrm{m}$ Evaporated Gold Film After Stabilization; Top Layer of Gold Has Been Sputtered off

length of a line to determine the loss per unit length of line. A plot of this data (Figure 7) shows that there is no significant difference between electroplated and evaporated $6 \mu \mathrm{m}$ thick gold. In Figure 8 it is seen that lower attenuation occurs in thicker gold, which is expected.

As seen in Figure 9, there appears to be no difference in reflection coefficient between $6 \mu \mathrm{m}$ evaporated and electroplated gold films. There does appear to be a resonance between 1200 and $1500 \mathrm{MHz}$, since the reflection coefficient is approximately an order of magnitude higher at these frequencies. This occurred for all metallization conditions and is therefore characteristic of the stripline design rather than of the metallization itself. 


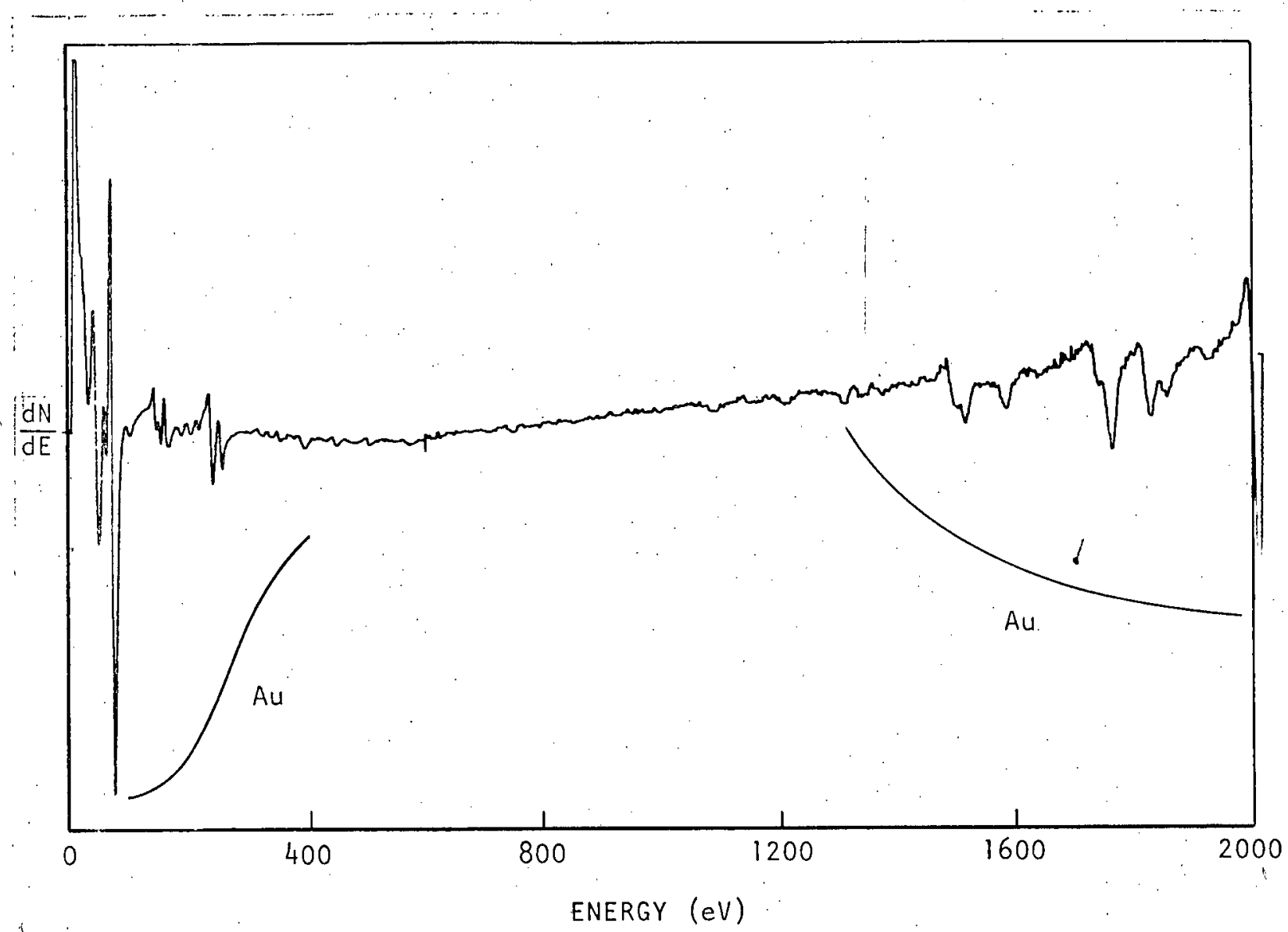

Figure 6. Auger Spectrograph of $6 \mu \mathrm{m}$ Electroplated Gold Film After Stabilization; Top Layer of Gold Has Been Sputtered Off

Via Resistance

A total of sixteen 95 by $114 \mathrm{~mm}$ ( 3.75 by 4.5 in.) substrates were used to evaluate the electrical resistance of vias metallized with electroplated gold and compare it to that of evaporated gold. Eight substrates had ultrasonically drilled holes and eight had green punched (punched in uncured ceramic) holes.

After the substrates were metallized, the vias were electrically isolated from one another (on the top side of the substrate) using a dry-film photolithography process. Via resistance was then measured using a four-point probe setup.

Resistance data is given in Figure 10. All via resistances were below the maximum allowable value of $10 \mathrm{~m} \Omega$. For green punched holes, the average via resistance of $6 \mu \mathrm{m}$ evaporated gold was approximately 7 to 10 times higher than that of $6 \mu \mathrm{m}$ electroplated 


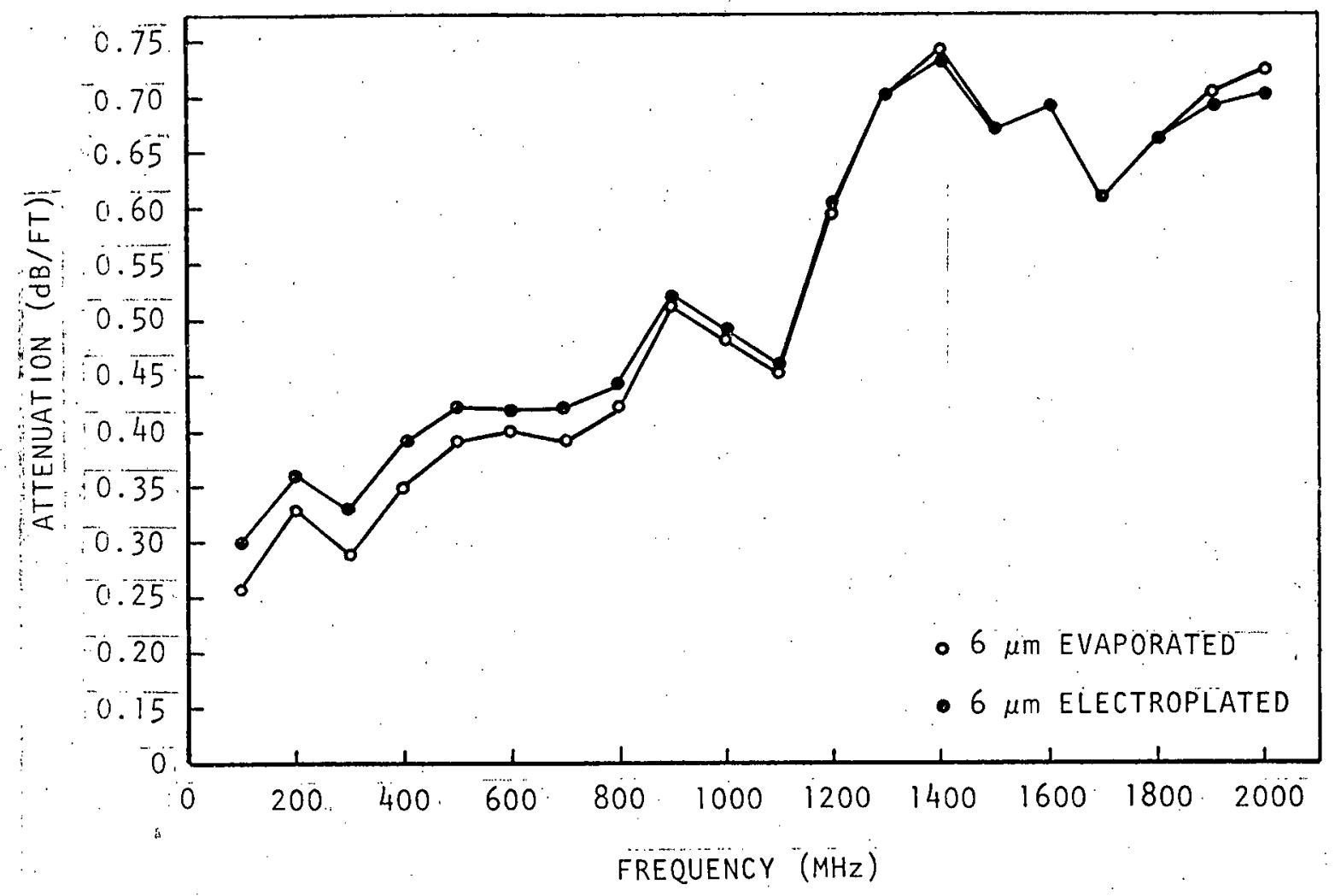

Figure 7. Plot of RF Stripline Attenuation Data for $6 \mu \mathrm{m}$ Evaporated and Electroplated Gold

gold. With $6 \mu \mathrm{m}$ evaporated gold, ultrasonically drilled vias had an average resistance at least 50 percent greater than green punched vias. Green punched and ultrasonic drilled holes had approximately the same via resistance, for a given diameter hole, for all thicknesses of plated gold. The average via resistance values given for 10 and $25 \mu \mathrm{m}$ plated gold and hole diameters greater than $762 \mu \mathrm{m}$ ( $30 \mathrm{mils}$ ) level off at about $0.12 \mathrm{~m} \Omega$, which is essentially the lower limit of resolution of the measuring equipment used.

\section{Conductor Definition and Resolution}

To determine if conductor lines could be suitably defined by standard photolithographic procedures, a total of 12 substrates were processed: 5 with $6 \mu \mathrm{m}$ evaporated gold, 3 electroplated to $6 \mu \mathrm{m}, 2$ electroplated to $10 \mu \mathrm{m}$, and 2 electroplated to $25 \mu \mathrm{m}$. The substrates used were 38 by $38 \mathrm{~mm}$ ( 1.5 by 1.5 in.), each of which was scribed out of the lower right hand corner of a 95 by $114 \mathrm{~mm}$ ( 3.75 by 4.5 in.) substrate. 


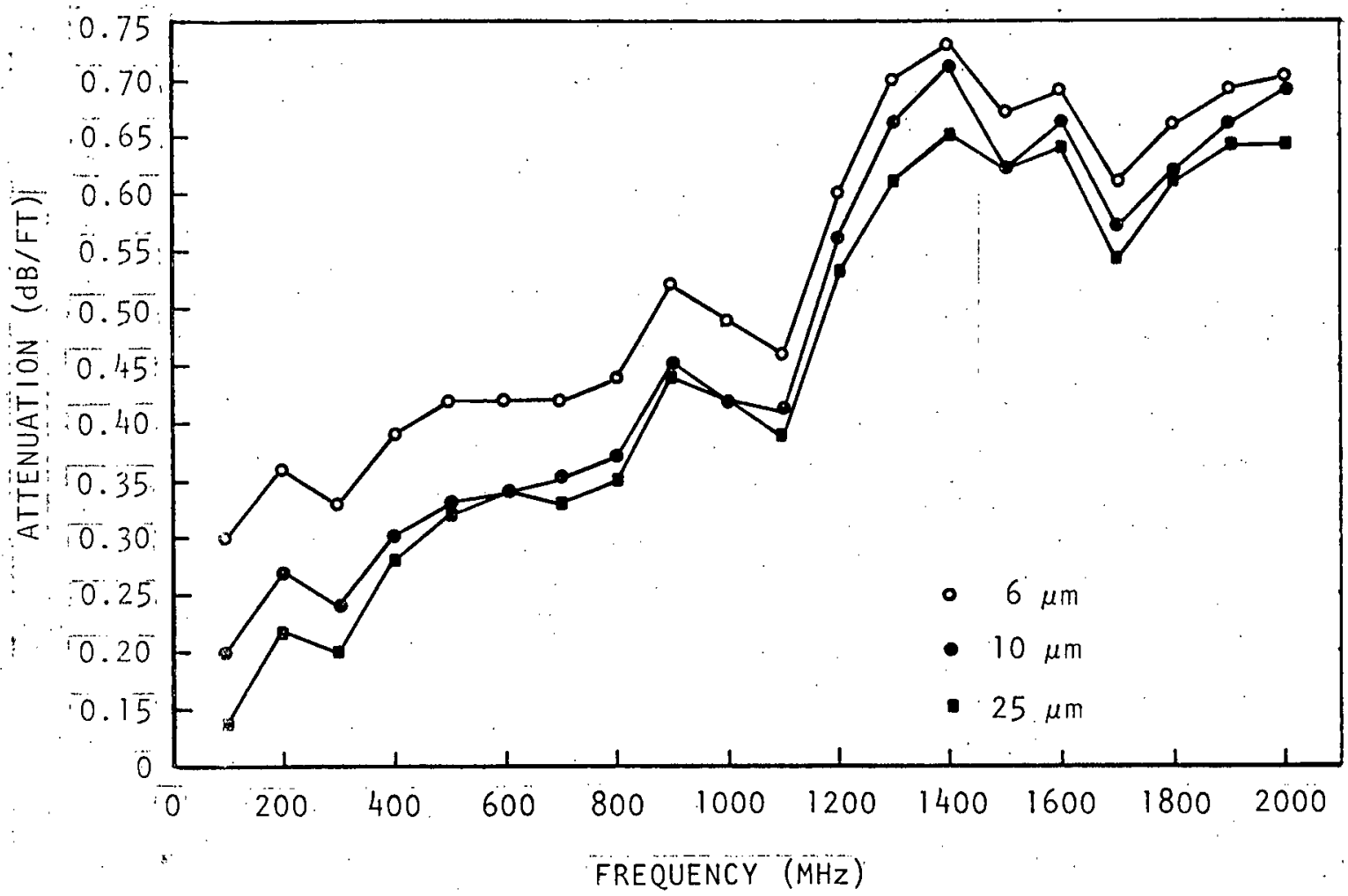

Figure 8. Plot of RF Stripline Attenuation Data for 6, 10 , and $25 \mu \mathrm{m}$ Electroplated Gold

All five evaporated substrates had been metallized in a common vacuum deposition process. The as-metallized substrates were laminated with dry-film photoresist (25 $\mu \mathrm{m}$ thick) and were then exposed with a pattern of varying line widths and spaces, ranging from $127 \mu \mathrm{m}$ ( $5 \mathrm{mil}$ ) lines with $508 \mu \mathrm{m}$ (20 mil) spacing to $51 \mu \mathrm{m}$ ( 2 mil) lines with $51 \mu \mathrm{m}$ spacing. The substrates were then individually immersion etched, using visual observation to determine when etching was complete. It was noted when etching $25 \mu \mathrm{m}$ thick films that the large amount of gold entering the solution caused the etching rate to decrease fairly rapidly.

After stripping away the remaining photoresist, line width measurements were made on all substrates. Five measurements were made in the $X$ direction, one on each of the five patterns, and three in the $Y$ direction. Measurements were not made on $51 \mu \mathrm{m}$ lines since they were not adequately defined. A summary of the line width data is given in Figure 11. 


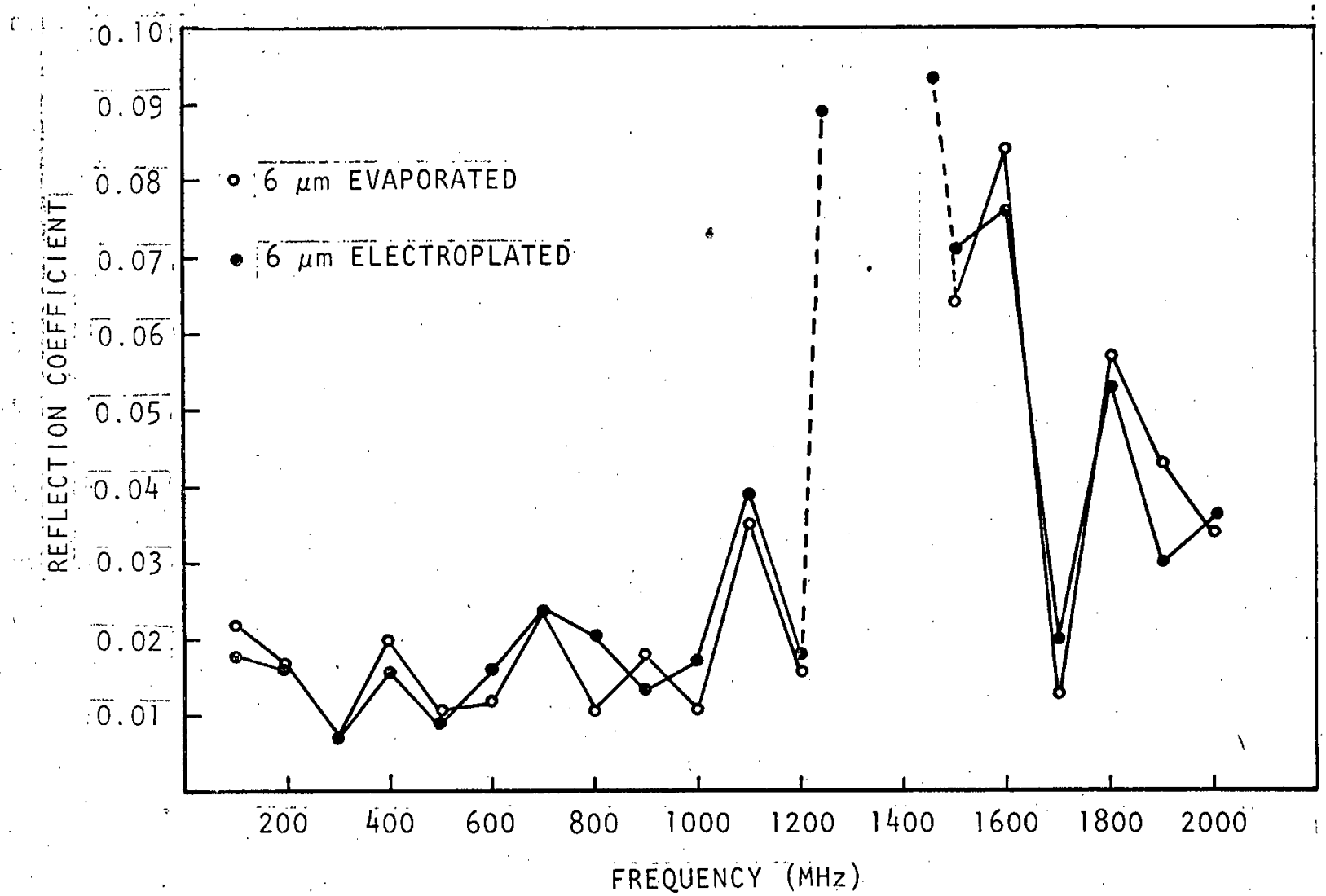

Figure 9. Plot of RF Stripline Reflection Coefficient Data for $6 \mu \mathrm{m}$ Evaporated and Electroplated Gold

For all metallization and line width conditions, the average line widths were less than the nominal values. For a given nominal ine width, the range of measured values for $6 \mu \mathrm{m}$ evaporated, $6 \mu \mathrm{m}$ electroplated, and $10 \mu \mathrm{m}$ electroplated films were approximately equal. For $25 \mu \mathrm{m}$ gold, the range of values had a much larger spread for all line width and spacing conditions. This could have been caused by variations in both the gold thickness and the etching rate across a substrate. When gold of this thickness is etched, a large amount of undercutting can occur; therefore, the amount and manner of agitation will have a critical effect on the accuracy and uniformity of the etching. It is believed that spray photolithographic processing will significantly improve conductor line definition and resolution of gold films greater than $6 \mu \mathrm{m}$, and will in fact be a necessity for films much greater than $10 \mu \mathrm{m}$ thick.

To qualitatively determine the line definitions obtainable on electroplated gold, the etched conductors in the centers of the 


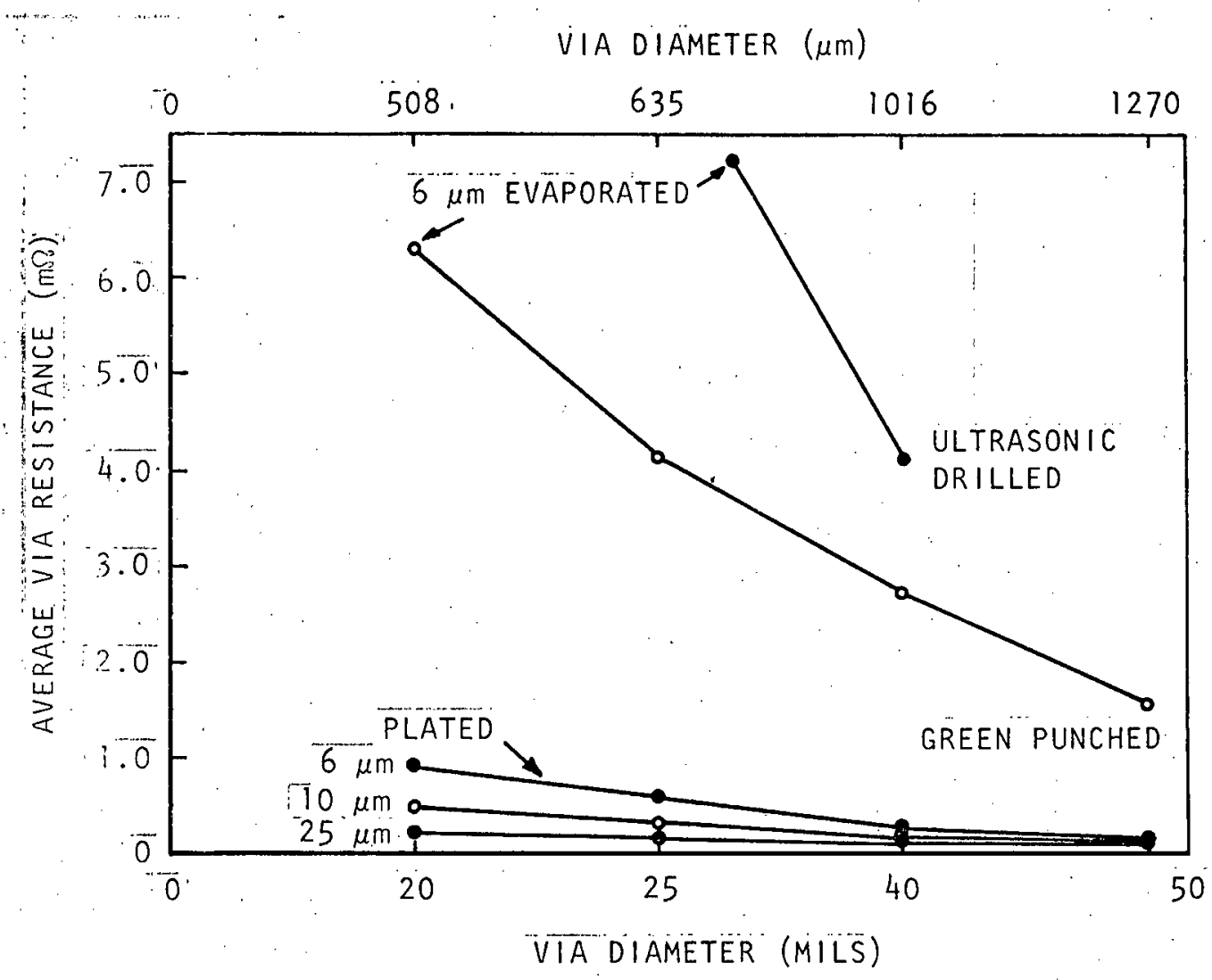

Figure 10. plot of Via Resistance iror Electroplated Versus Evaporated Gold

patterns on $6 \mu \mathrm{m}$ thick films were microscopically examined and a well-defined line. was selected. This was similarly done on a $6 \mu \mathrm{m}$ evaporated substrate. Photomicrographs of these are shown in Figure 12: Although this was by no means a quantitative or objective measure of line definition, it does indicate that concuctor edge definition comparable to that obtainable on evaporated gold can be produced on electroplated gold films.

\section{Solder Wettability}

Twenty substrates were used in the evaluation of the solderability of electroplated gold: 5 evaporated to $6 \mu \mathrm{m}, 6$ electroplated to $6 \mu \mathrm{m}, 4$ electroplated to $10 \mu \mathrm{m}$, and 5 electroplated to 25. $\mu \mathrm{m}$. The 25 by $25 \mathrm{~mm}$ ( 1 by 1 in.) substrates, which were laser scribed out of larger substrates, were initially stabilized ( 2 hours at $300^{\circ} \mathrm{C}$ ), ceric ammonium nitrate (CAN) etched, and TC cleaned. To assure their cleanliness, the substrates were rinsed in thichloroethylene before the solder spread test was performed. A $12.7 \mathrm{~mm}$ (0.5 in.) length of $0.76 \mathrm{~mm}$ ( 0.030 in.) diameter 50:50 PbIn solder was placed on each substrate along with mildly 

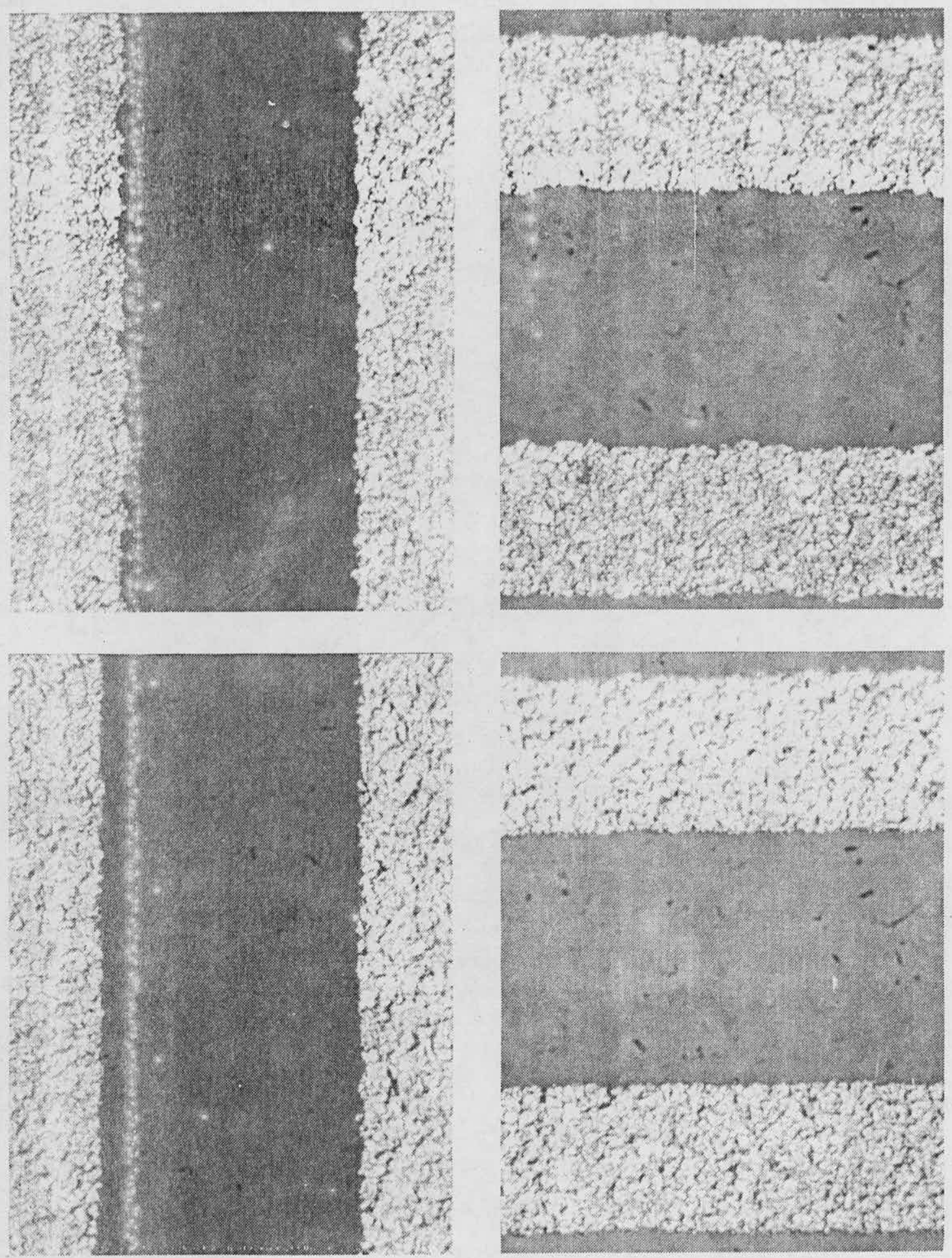

Figure 12. Conductor Edge Definition of 6 um Evaporated (Top) and Electroplated (Bottom) Gold (740X) 
activated flux. Using a rotary reflow solder system, the substrates were heated to $264^{\circ} \mathrm{C}$ for 5 seconds. This temperature was used because the liquidus temperature of 50:50 $\mathrm{PbIn}$ solder is $209^{\circ} \mathrm{C}$ and this solder spread test typically uses a temperature $55^{\circ} \mathrm{C}$ higher than the liquidus temperature. After heating, the substrates were rapidly cooled and handled carefully to prevent jarring the molten solder.

The height of the solder. with respect to the substrate surface was measured after the flux was cleaned off. A linear variable differential transformer (LVDT) probe setup, which measures the highest point of the solder with the frame of the fixture resting on the substrate surface, was used. The solder spread factor, a measure of the solder wettability of the gold metallization, is calculated from

S.F $:=\frac{D-H}{D} \times 100$

where

$D=$ the diameter of a sphere having a volume equal to the original volume of solder used, and

$H=$ the height with respect to the substrate surface of the solder after melting.

The calculated spread factor values are given in Table 2 . There is apparently no difference between the solder wettability of evaporated and electroplated gold or between pre-sputtered and pre-evaporated electroplated gold. Any variance in the values given is considered to be within the experimental error of measurements made.

\section{Lead Frame Bondability}

To evaluate the thermocompression bondability of the electroplated gold films $127 \mu \mathrm{m}$ ( 0.005 in.) thick gold-plated copper lead frames were bonded to the substrates and then pull tested to determine the quality of the bond. This evaluation was made on eighty 25 by $25 \mathrm{~mm}$ ( 1 by 1 in.) substrates which had been laser scribed out of twenty 95 by $114 \mathrm{~mm}$ ( 3.75 by 4.50 in.) substrates: The sample included 20 substrates with $6 \mu \mathrm{m}$ thick vacuum evaporated gold, 24 electroplated. to $6 \mu \mathrm{m}, 16$ plated to $10 \mu \mathrm{m}$, and 20 plated to $25 \mu \mathrm{m}$. Bonding was performed on the substrates both before and after resistor stabilization ( 2 hours at $300^{\circ} \mathrm{C}$ ); however, none of the substrates had been processed through photolithography. All substrates and lead frames were subjected to the standard "cleaning for bonding" process before thermocompression boinding. 
Table 2. Solder Spread Factor

\begin{tabular}{|c|c|}
\hline Substrate & $\begin{array}{l}\text { Spread } \\
\text { Factor }\end{array}$ \\
\hline \multicolumn{2}{|c|}{$6 \mu \mathrm{m}$ Evaporated Gold $(\bar{x}=91.17)$} \\
\hline $\begin{array}{l}\text { E304104 } \\
\text { E304204 } \\
\text { E304304 } \\
\text { E304404 } \\
\text { E304504 }\end{array}$ & $\begin{array}{l}90.19 \\
92.93 \\
93.50 \\
90.76 \\
88.48\end{array}$ \\
\hline 6. $\mu \mathrm{m}$ Electroplated $\mathrm{C}$ & Gold $(\bar{x}=90.99)$ \\
\hline $\begin{array}{l}\text { A100104 } \\
\text { A100204 } \\
\text { A222104 } \\
\text { A222204 } \\
\text { A } 131104 \\
\text { A230104 }\end{array}$ & $\begin{array}{l}93.16 \\
89.62 \\
90.65 \\
88.37 \\
90.54 \\
93.61\end{array}$ \\
\hline $10 \mu \mathrm{m}$ Electroplated & Gold $(\bar{x}=91.22)$ \\
\hline $\begin{array}{l}\mathrm{B} 100304 \\
\mathrm{~B} 230204 \\
\mathrm{~B} 131204 \\
\mathrm{~B} 222304\end{array}$ & $\begin{array}{l}89.97 \\
90.54 \\
92.82 \\
91.56\end{array}$ \\
\hline $25 \mu \mathrm{m}$ Electroplated & Gold $(\bar{x}=91.04)$ \\
\hline $\begin{array}{l}\text { D230404 } \\
\text { D222304 } \\
\text { D1314.04 } \\
\text { D131504 } \\
\text { C100404 }\end{array}$ & $\begin{array}{l}91.11 \\
88.71 \\
90.88 \\
90.88 \\
93.61\end{array}$ \\
\hline
\end{tabular}


The bonding was done on a laboratory bonder with a straight rail. bonding tool; using typical operating parameters for $6 \mu \mathrm{m}$ evaporated gold films: tool temperature of $680^{\circ} \mathrm{C}$; bond force of $1.67 \mathrm{kN}$ (375 $1 \mathrm{~b})$; and bond time of 30 seconds. No attempts were made to modify the operating parameters to improve the bonding process for the different thicknesses of electroplated gold.

The 90 degree peel test was used to evaluate the quality of the thermocompression bonds. This test involves bending the lead upward to form a 90 degree angle with the substrate, and then pulling the lead until it either breaks for delaminates from the substrate. The maximum force attained during pulling was measured and recorded. To avoid stressing the leads near the bond zone and thus influencing the pull strength and mode of failure, the leads were supported between the bonded area and the edge of the substrate during the bending operation.

As-Metallized Substrates

Two lead frames were bonded to each of 20 substrates which had been subjected to no post-metallization processing other than a pre-bond cleaning operation. The substrates used had been taken from the same relative location on each of the 20 larger substrates. Alternate leads were pull tested, providing a total of 20 leads on each substrate. A summary of the pull test data is given in Table 3 .

The lowest average pull strength occurred on $6 \mu \mathrm{m}$ electroplated films--on which one lead failed at less than the minimum requirement of $3.36 \mathrm{~N}(0.75 \mathrm{lb})$. After pulling this lead, ceramic was visible over more than 30 percent of the bond zone, with evidence that some ceramic had been pulled out of the substrate by the substrate metallization. Of the non-heel failures on $6 \mu \mathrm{m}$ electroplated gold, 96 percent had ceramic visible within the bond zone, and the majority of these showed evidence of ceramic pull-out. This has since been found to be a common occurrence on the brand of substrates used in this evaluation. A possible explanation for the higher percentage of this type of failure on $6 \mu \mathrm{m}$ plated films than on $6 \mu \mathrm{m}$ evaporated films can be given by considering the stress transmitted to the substrate during bonding. The front side thickness of the nominal $6 \mu \mathrm{m}$ evaporated gold films ranged from 7.8 to $8.5 \mu \mathrm{m}$, with an average thickness of $8.1 \mu \mathrm{m}$, while that of the $6 \mu \mathrm{m}$ electroplated films ranged from 6.0 to 7.8 , with an average of 6.8 . The thinner gold on the plated substrates, along with the slightly harder gold deposit, would cause the bonding force to impose a higher stress on the substrate in the bond zone. This apparently caused some ceramic microcracking. In any case, these types of failures do not indicate poor thermocompression bondability of electroplated gold films; rather, they indicate that the bonding parameters need to be modified for bonding to $6 \mu \mathrm{m}$ electroplated gold on this brand of substrates. 
Table 3. Lead Frame Bonding Evaluation of Evaporated and Electroplated Substrates

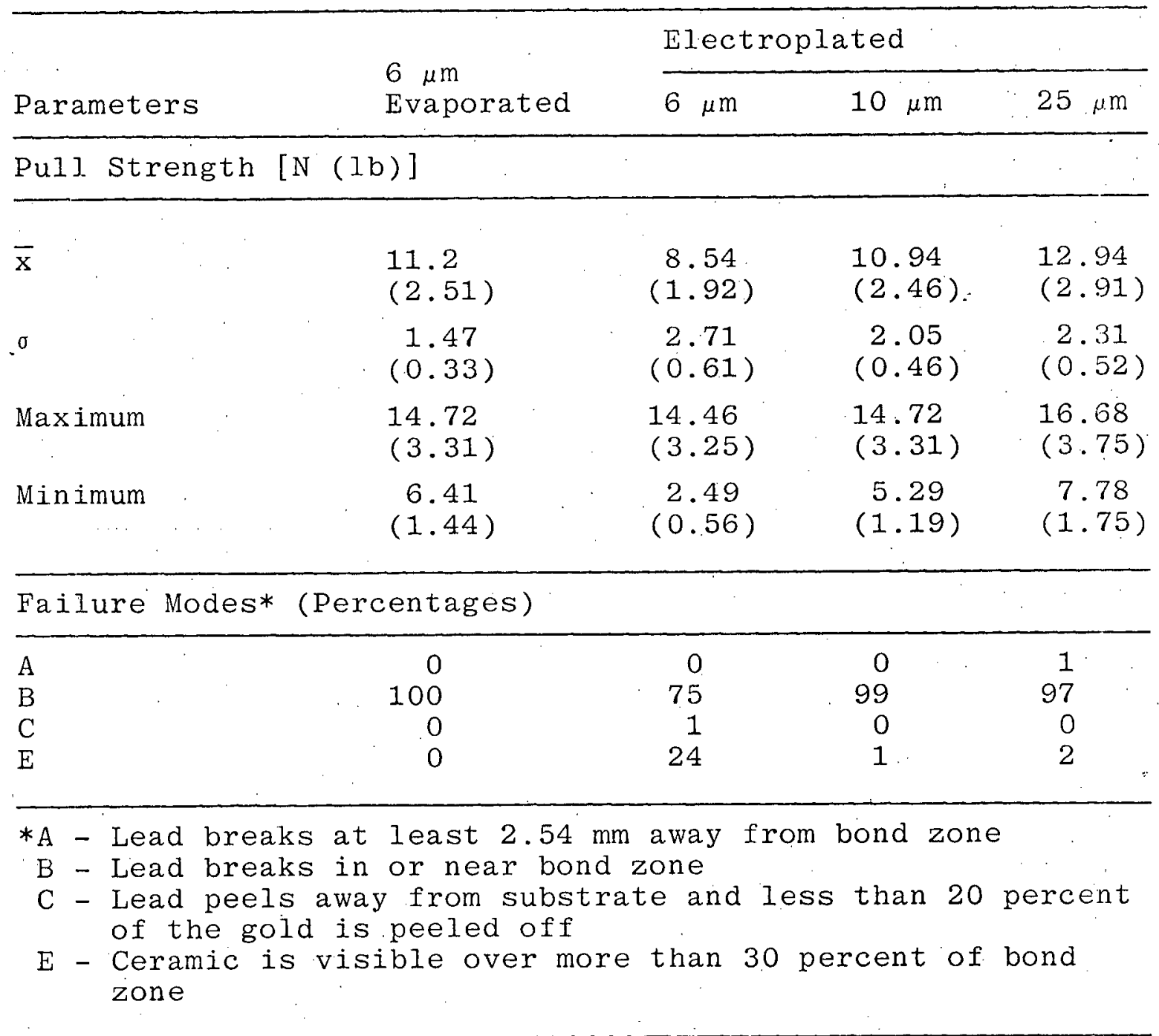

All substrates with 10 and $25 \mu \mathrm{m}$ electroplated gold met the minimum specification of 60 percent heel failures and $3.36 \mathrm{~N}$ ( 0.75 lb) minimum pull strength. The $25 \mu \mathrm{m}$ plated substrates had the highest average, maximum, and minimum pull strengths of the four metallization types tested. One lead frame broke greater than $2.5 \mathrm{~mm}$ ( 0.100 in.) iaway from the bond zone with a pul.l strength of $16.68 \mathrm{~N}(3.75 \mathrm{lb})$, indicating that the strength of the thermocompression bond was greater than the tensile strength of the lead frame: 
Measurements were made of the lead frame deformation which occurred during bonding to determine if the higher pull strengths on the $25 \mu \mathrm{m}$ plated gold films were a result of lower deformation.

Deformation greater than the minimum required for a good thermocompression bond will merely. weaken the lead frame near the bond zone, thereby causing a lower strength heel failure to occur. The deformation measurements were made using a light section microscope which measures the distance from the top of the substrate metallization to the top surface of the bonded portion of the lead frame. Percent deformation was then calculated using the nominal lead frame thickness value of $137 \mu \mathrm{m}(0.0054$ in.).

The average deformation values were 57.4, 54.9, 56.6, and 58.2 percent for $6 \mu \mathrm{m}$ evaporated, and 6,10 , and $25 \mu \mathrm{m}$ electroplated films, respectively. The higher deformation value for the $25 \mu \mathrm{m}$ films is not consistent with the pull test data. However, it was evident that the substrate metallization had been squashed out around the lead frame bonded to the $25 \mu \mathrm{m}$ thick plated gold, but not on the bond made to the thinner evaporated gold. This indicates that bonding to the thicker gold films causes the lead frame to sink: into the substrate metallization, thereby causing less deformation of the lead itself. This would explain the higher pull strengths seen on the thicker plated gold films.

Stabilized and CAN Etched Substrates

Two lead frames were bonded to each of 20 substrates which had been subjected to stabilization ( 2 hours at $300^{\circ} \mathrm{C}$ ), followed by a CAN etch and pre-bond cleaning process. These substrates did not receive any photolithographic processing. It was noted that the stabilization and CAN etching caused the back side metalization to completely delaminate from all five of the $6 \mu \mathrm{m}$ evaporated substrates. A summary of the pull test data is given in Table 4.

Al1 substrates met the minimum bondability requirements: On $6 \mu \mathrm{m}$ films, electroplated gold had slightly lower lead frame pull strengths than did evaporated gold, while $25 \mu \mathrm{m}$ plated films had the highest values of average, maximum, and minimum pull strengths. Once again, a significant number of " $E$ " failures (ceramic visible within bond zone), with evidence of ceramic pull out, occurred on $6 \mu \mathrm{m}$ plated films.

A comparison of pull strength data for pre-sputtered and preevaporated electroplated films is given in Table 5. For all thicknesses of plated films, the average, maximum, and minimum pull strengths for pre-sputtered films were equal to or greater. than those for pre-evaporated films. 
Table 4. Lead Frame Bonding Evaluation of Stabilized and CAN Etched Evaporated and Electroplated Substrates Without Photolithography

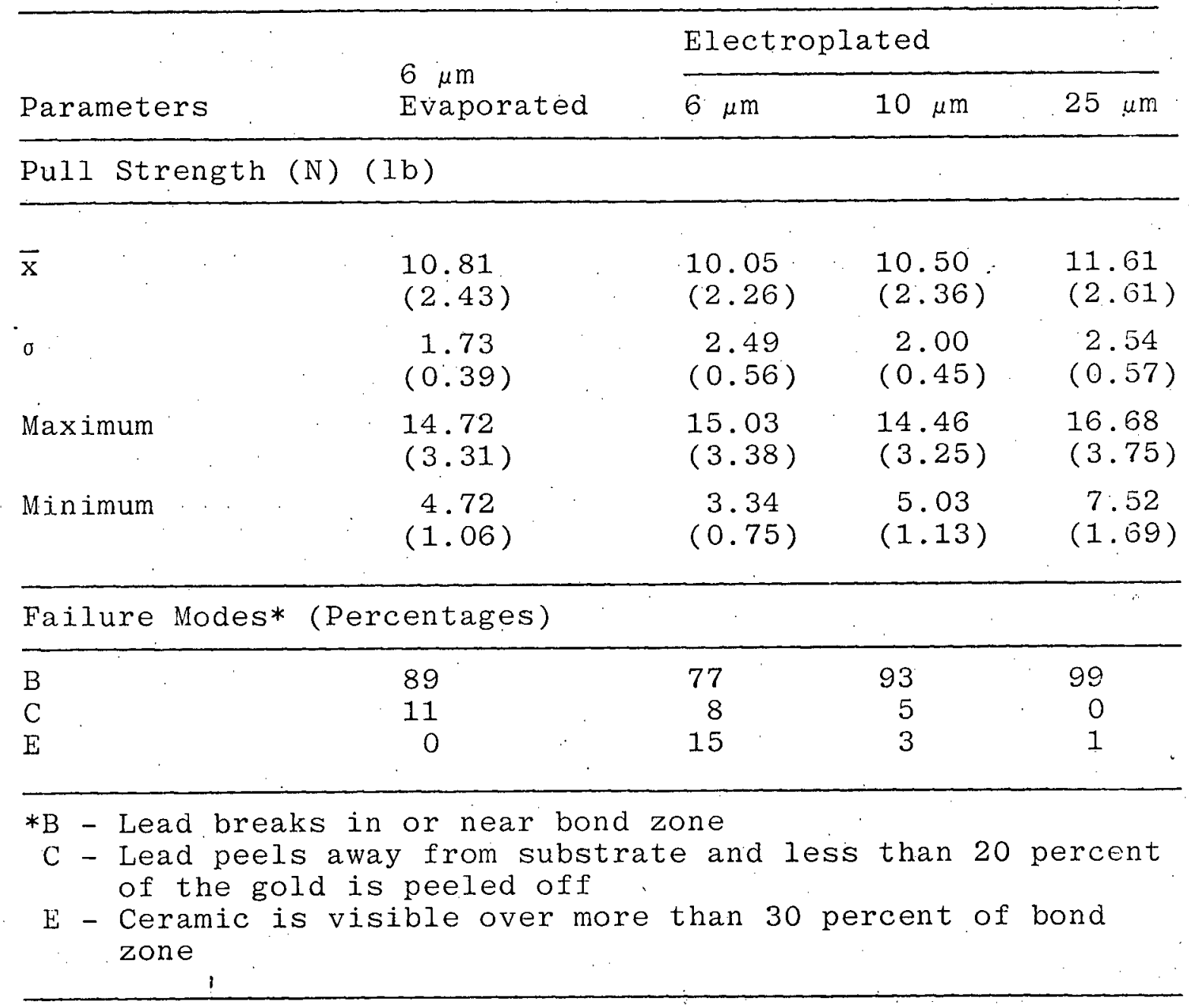

A comparison of data for as-metallized versus stabilized and CAN etched substrates is given in Figure 13. With the exception of $6 \mu \mathrm{m}$ plated substrates, the stabilized and CAN etched substrates. had pull strengths slightly lower than those for as-metallized substrates. Since these were two different groups of substrates and were processed separately after metallization, the differences in pull strengths could have been caused by variations in the cleaning or bonding operations. Substrates pre-sputtered and electroplated to $25 \mu \mathrm{m}$ had the best pull strength results, with 100 percent heel failures both before and after the stabilization and CAN etch processes. 
Table 5. Lead Frame Bonding Evaluation of Stabilized and CAN Etched Pre-Sputtered and Pre-Evaporated Substrates Without Photolithography

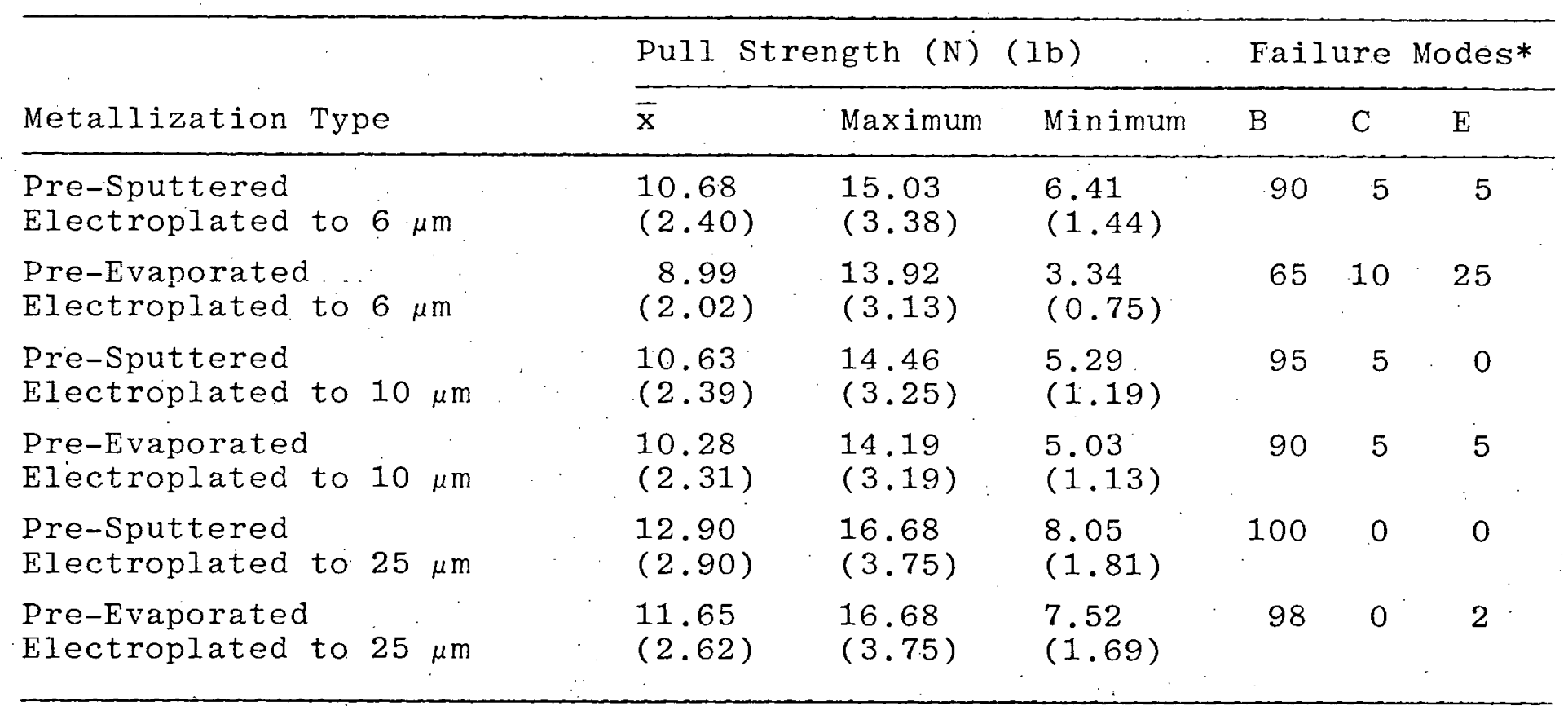

\section{*Percentages}




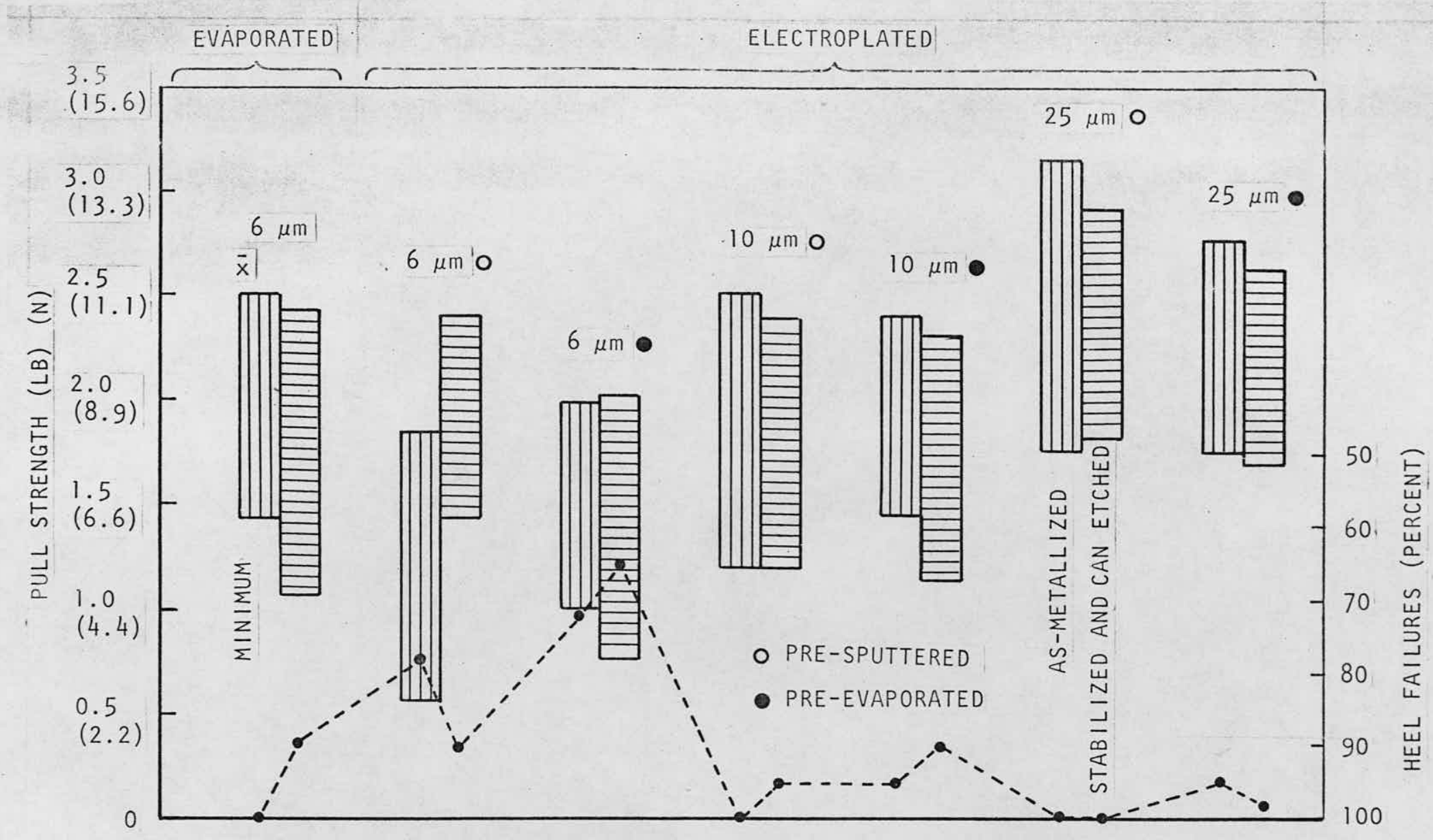

Figure 13. Effect of Stabilization and CAN Etch on Lead Frame Bonds 
Temperature Cycling Effect on Bonds

Two lead frames were bonded to each of 20 substrates which had been stabilized and CAN etched but not photoprocessed. The substrates were then subjected to 30 temperature cycles from $-55^{\circ} \mathrm{C}$ to $+125^{\circ} \mathrm{C}$, with a temperature change rate of $20^{\circ} \mathrm{C}$ per minute and a 15-minute dwell time at each temperature extreme. Approximately one-fourth of the lead frames on each substrate were pull tested before temperature cycling, and after 10, 20, and 30 cycles. Bond pad thickness measurements showed that the thickness varied approximately $13 \mu \mathrm{m}$ ( $0.0005 \mathrm{in.}$ ) across a given lead frame. This probably was caused either by misalignment of the bonder or by a variation in the thickness of the Kapton spacer used between the substrate and the bonder work table. Lead frames pulled at each of the four intervals were selected to compensate for the variations in bond deformation, with the same pattern of leads being: pulled on all substrates.

The pull test data is given in Figure 14. All substrates met the minimum bondability requirements. Temperature cycling appeared to cause no significant degradation of the thermocompression bonds. Substrates plated to $25 \mu \mathrm{m}$ produced the best results with regard to both pull strength and failure modes, with pre-sputtered films having slightly higher strengths than pre-evaporated films.

\section{Thermal Aging Effect on Bonds}

Two lead frames were bonded to each of 20 substrates which had been stabilized and CAN etched but not photoprocessed. The substrates were then subjected to $150^{\circ} \mathrm{C}$ for a total of 1000 hours.

Approximately one-fourth of the lead frames on each substrate were pull tested before thermal aging, and after 250, 500, and 1000 hours. The lead frames were pulled in the same pattern as was used for the temperature cycling evaluation. Summarized pull test data is given in Figure 15. All substrates met the minimum bondability requirements. Thermal aging did not cause any significant degradation of the thermocompression bonds.

\section{Accomplishments}

Electroplated gold 6,10 , and $25 \mu \mathrm{m}$ thick was investigated and was found to be feasible for use on hybrid microcircuit substrates. The via resistance obtained on electroplated substrates was superior to that obtained on evaporated substrates. The solder wettability, thermocompression bondability, RF electrical characteristics, conductor definition, and environmental stability of electroplated gold were found to be compatible with HMC requirements and fabrication processes and comparable to those properties of evaporated gold films. The variation in thickness across one side of a large substrate was not as good as that obtained with evaporated gold; however, it is believed that this can be significantly improved by modifying the plating fixture. 


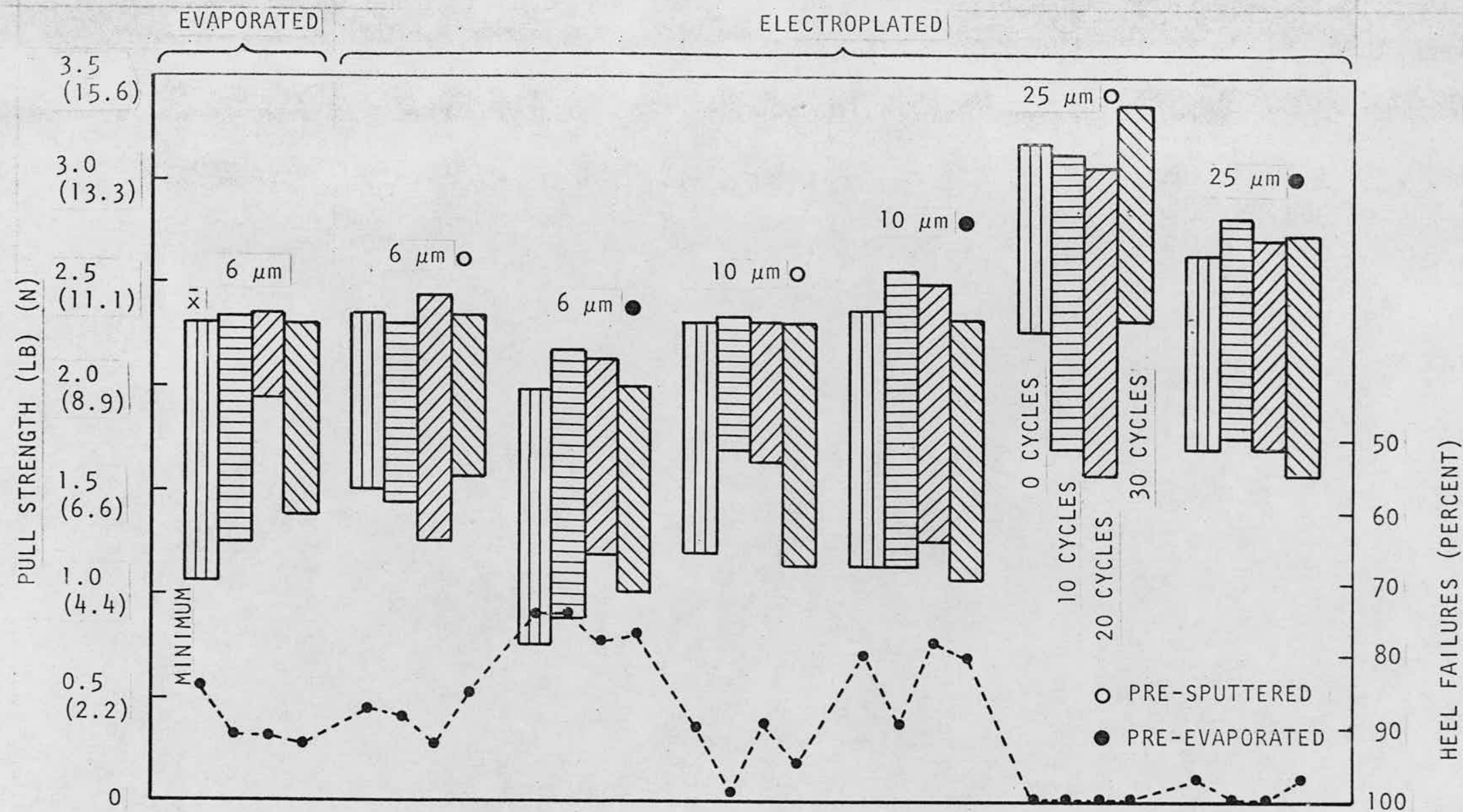

Figure 14. Effect of Temperature Cycling on Lead Frame Bonds 


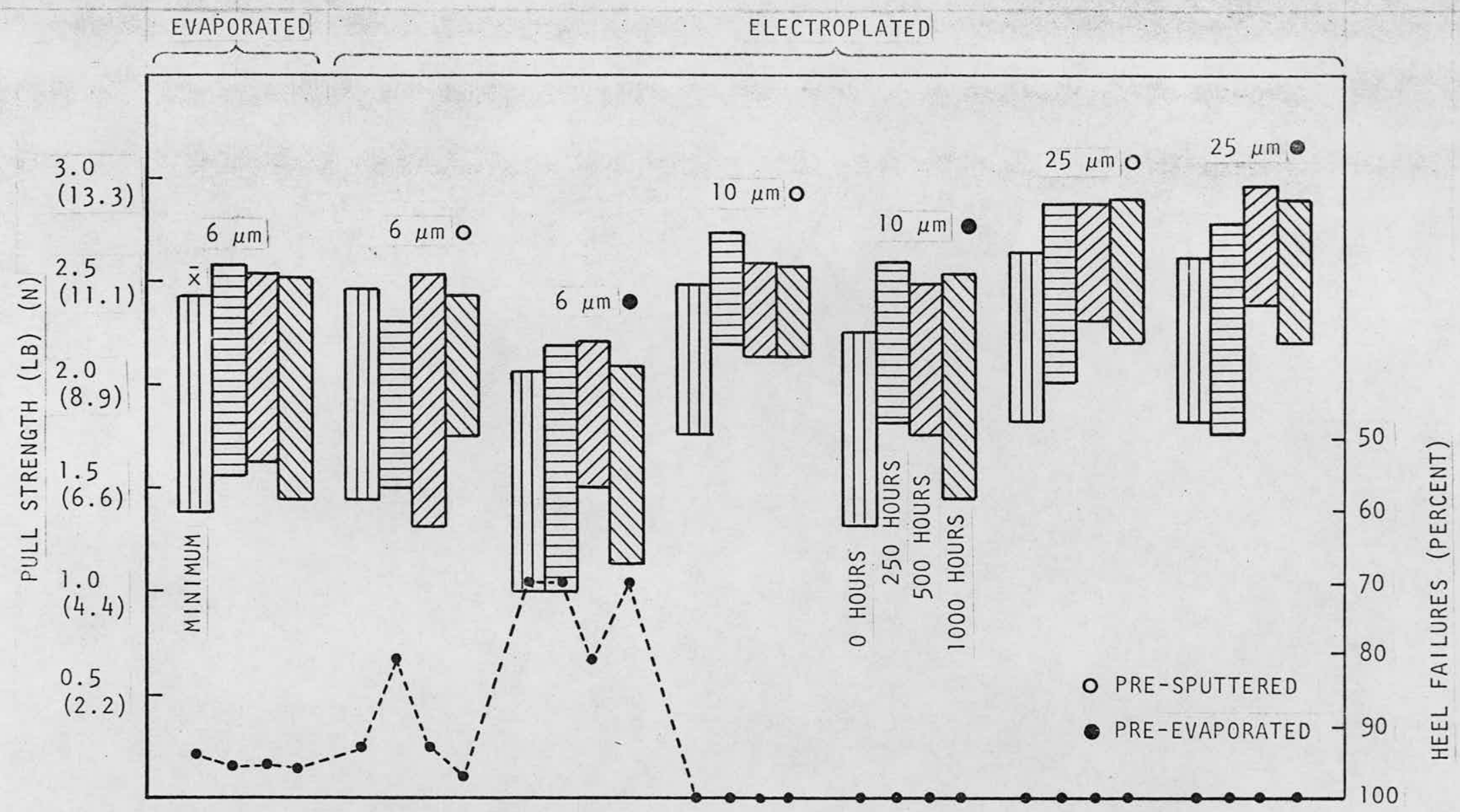

Figure 15. Effect of Thermal Aging $\left(150^{\circ} \mathrm{C}\right)$ on Lead Frame Bonds 


\section{References}

${ }^{1}$ D. L. Rehrig, "Effect of Deposition Method on Porosity in Gold Thin Films," Plating, Volume 61, Number 43, 1974.

${ }^{2} \mathrm{~J}$. M. Leeds and M. Clarke, "The Effects of Plating Condition on Porosity in Gold Electrodeposits, "Transactions of the Institute of Metal Finishing, Volume 43, Number 50, 1965. 


\section{Bibliography}

Aramati, V. S., and others. "Thin-Film Microwave Integrated Circuits." IEEE Transactions on Parts, Hybrids, and Packaging, Volume PHP-12, Number 4, December, 1976, pp 309-316.

Brauer, W., and others. "Reproducible Methods for the Fabrication of Microwave Strip Lines of High Precision and Reliability." Solid State Technology, December, 1976, $\mathrm{pp} \cdot 67-73$.

Cady, J. R., and P. S. Wilcox. "Mechanical Properties of Electroplated Gold." Plating, February, 1973; pp 139-145.

Curran, J. E., and others. "A Technology of Thin-Film Hybrid Microwave Circuits." IEEE Transactions on Parts, Hybrids, and Packaging, Volume PHP-12, Number 4, December, 1976, pp $309-316$.

Duva,.R., and D. G. Foulke. "Properties of Some Gold Electrodeposits." Plating, October, 1968.

Leeds, J. M., and M. Clarke. "The Effects of Plating Condition on Porosity in Gold Electrodeposits." Transactions of the Institute of Metal Finishing, Volume 43, Number 50, 1965.

Melrose, S. P. G., and B. S. Cooper. "Beta Backscatter Measurements of Casting Thickness." Transactions of the Institute of Metal Finishing, Volume 45, 1967, pp 199-205.

Norwood, D., and others. "Manufacturing Processes for Hybrid Microcircuits Containing Vias." IEEE Transactions on Parts, Hybrids, and Packaging, Volume PHP-12, Number 4, December, 1976, pp 323-335.

Panousis, N. T., and H. B. Bonham. "Bonding Degradation jn the Tantalum-Nitride/Chromium/Gold Metallization System." Reiiability Physics Symposium, April, 1973.

Pcihoda; W. W., and A. E. Walker, Jr. "Production Plating of Thin-Film Circuits." Electronic Packaging and Production, June, 1975, pp 74-78.

Rehrig, D. L. "Lffect of Deposition Method on Porosity in Gold Thin Films." Plating, Volume 61, Number 43, 1974. 